\section{SUMMARY}

1. Three strains of Cladosporium fulvum Cooke, a wild strain and two mutants, were grown on Czapek-Dox medium supplemented by Marmite, and the mycelial pigments were examined.

2. The pigment produced by one mutant was frangula-emodin; no pigment was obtained from the other mutant examined.

3. The wild strain produced a new trihydroxymethylanthraquinone named cladofulvin, which yielded a triacetate and di- and tri-O-methyl derivatives. Distillation with zine dust yielded 2-methylanthracene; oxidation of the dimethyl derivative of cladofulvin gave hemipinic acid.

4. These facts, together with ultraviolet- and infrared-absorption spectra, indicated that cladofulvin has the structure 1,2,8-trihydroxy-7-methylanthraquinone.
We thank Miss I. Tanner of Parke, Davis and Co. Ltd. for the infrared determinations. For the Uvispek instrument used we are indebted to a grant from the Central Research Fund of London University.

\section{REFERENCES}

Birkinshaw, J. H. (1955). Biochem. J. 59, 485.

Birkinshaw, J. H. \& Gourlay, R. (1961). Biochem. J. 80, 387.

Day, P. R. (1957). Nature, Lond., 179, 1141.

Day, P. R. \& Sherratt, H. S. A. (1958). Biochem. J. 68, $11 P$.

Hasper, E. V. (1925). Z. PflKrankh. 35, 112.

Hay, J. E. \& Haynes, L. J. (1956). J. chem. Soc. p. 3141.

Haynes, L. J. \& Henderson, J. I. (1960). Chem. \& Ind. p. 50.

Haynes, L. J., Henderson, J. I. \& Tyler, J. M. (1960). J. chem. Soc. p. 4879.

Kögl, F. \& Postowsky, J. J. (1925). Liebigs Ann. 444, 1.

Biochem. J. (1962) 85, 530

\title{
Biochemical Studies on the Developing Avian Embryo
}

\section{UBIQUINONE AND SOME OTHER UNSAPONIFIABLE LIPIDS*}

\author{
By J. F. PENNOCK, GERTRUDE NEISS AND H. R. MAHLER \\ Department of Chemistry, Indiana University, Bloomington, Indiana, U.S.A.
}

(Received 7 June 1962)

The presence of ubiquinone-50 in embryonic chick heart and liver was reported by Brand, Dahl \& Mahler (1960). The ubiquinone content of mitochondria was of the same order as that of similar preparations from adult organisms. It was of interest to know whether the egg provided the developing embryo with all the ubiquinone it required, or if the embryo was capable of synthesizing the quinone. This paper describes work on the presence of ubiquinone in egg yolk and on the increasing amount found in the embryo during development.

A preliminary experiment showed that in hen's eggs the unsaponifiable lipids are concentrated in the yolk, whereas negligible amounts are present in the albumin. Lipids are a very important constituent of the yolk and in fact make up some $33 \%$ of its total weight. Of the lipids present, triglycerides amount to $62.3 \%$ and phospholipids to $32.8 \%$, sterol, vitamins and provitamins adding up to the remaining $4.9 \%$ (Romanoff \& Romanoff, 1949). In this study of avian-embryo lipids, the components examined include sterol, ergosterol,

\footnotetext{
* Part 4: Brand, Dahl \& Mahler (1960).
}

vitamins $A$ and $\mathbf{E}$, as well as ubiquinone, all or some of which may play fundamental roles in the development of the embryo and in hatching.

\section{MATERIALS}

Cornish White Rock hatching eggs were obtained from the Farm Bureau Hatchery, Harrisburgh, Pa., U.S.A. Column chromatography was carried out on neutral alumina (type AG7, Bio-Rad Laboratories, Richmond, California, U.S.A.), and silica gel G (E. Merck, Darmstadt, Germany) was used as adsorbent for thin-layer chromatography. Light petroleum (b.p. $30-60^{\circ}$ ) was dried over sodium wire and distilled. Analytical grade anhydrous diethyl ether was obtained from Mallinckrodt (New York). A supply of tocopherols (DL-tocol, DL- $\alpha$-tocopherol, DL- $\beta$ tocopherol, D- $\gamma$-tocopherol and DL- 2-tocopherol) were kindly given by Dr J. Green of Vitamins Ltd., Tadworth, Surrey.

\section{METHODS}

Spectrophotometry. Ultraviolet-absorption spectra were measured in either the Cary 11 or the Cary 14 recording spectrophotometer with cyclohexane (Fisher Spectroanalysed Certified Reagent) as solvent. The Bausch and Lomb Spectronic 20 colorimeter was used for measurements in the visible range. 
Preparation of tissue. Yolks of unincubated eggs were separated from the albumin mechanically and the combined yolks (60 g.) from three eggs were used for a determination. Other eggs were incubated for 11, 15, 17, 19 and 21 days (hatching occurs at 21 days) and in each case the chick embryo was separated from the residual yolk. For each determination the contents of three eggs were used, i.e. three chick embryos and three residual yolks. The embryos, which died shortly after removal from the egg, were homogenized in a Waring Blendor before saponification.

Hydrolysis of the tissue. The yolk or minced embryo $(x \mathrm{~g}$.) was added to a mixture of $x \mathrm{ml}$. of methanolic $0.5 \%(w / v)$ pyrogallol and $0.5 x \mathrm{ml}$. of aq. $60 \%(\mathrm{w} / \mathrm{v}) \mathrm{KOH}$. The mixture was refluxed for $45 \mathrm{~min}$. and was then cooled by the addition of $3 x \mathrm{ml}$. of water. The mixture was extracted five times with ether and the combined extracts were washed free from alkali, dried over anhydrous sodium sulphate, filtered at the pump and evaporated to dryness, finally under nitrogen. This procedure usually resulted in the hydrolysis of virtually all triglycerides and phospholipids.

Crystallization of sterol. The main bulk of the sterols was removed by dissolving the unsaponifiable lipids in warm light petroleum (b.p. $30-60^{\circ}$ ) and cooling to precipitate sterol, which could be filtered off at the pump.

Vitamin A. A tenth of the unsaponifiable lipids was taken for a vitamin A assay by the Carr \& Price (1926) reaction. The sample was dissolved in chloroform and to $1 \mathrm{ml}$. (containing 5-20 i.u. of vitamin A) was added 1 drop of acetic anhydride and $4 \mathrm{ml}$. of antimony trichloride reagent $\left[30 \%(\mathrm{w} / \mathrm{v}) \mathrm{SbCl}_{3}\right.$ in $\left.\mathrm{CHCl}_{3}\right]$. The blue colour was measured at $617 \mathrm{~m} \mu$ after 5-10 sec. and the vitamin $A$ content estimated by using an $E_{1}^{1 \%}$. value of 6000 (Glover, Goodwin \& Morton, 1947).

Chromatography. The unsaponifiable lipids were chromatographed on neutral alumina, partially deactivated with water to Brockmann grade 3. Fractions eluted by light petroleum, 4, 6, 10 and $30 \%(v / v)$ ether in light petroleum, ether and finally methylal were collected. The light-petroleum fraction exhibited peaks at 230 and $255 \mathrm{~m} \mu$ and the infrared spectrum indicated mainly saturated hydrocarbons. Ubiquinone was in the fractions eluted by the 4 and $6 \%$ ether in light petroleum, as indicated by an absorption maximum near $272 \mathrm{~m} \mu$. The fractions containing ubiquinone were combined and the ubiquinone content was determined by borohydride (tetrahydroborate) reduction in ethanol (Crane, Lester, Widmer \& Hatefi, 1959). The fractions eluted by 6 and $10 \%$ ether in light petroleum showed maxima near $295 \mathrm{~m} \mu$, indicating the presence of tocopherol. Total tocopherol was determined by the Emmerie-Engel reaction (see below): The $30 \%$ ether in light petroleum eluted a white solid which appeared to be sterol, and the ultraviolet-absorption spectrum showed $\lambda_{\max }$. at $262,271,282,293$ and $327 \mathrm{~m} \mu$, suggesting the presence of ergosterol and vitamin A. This fraction was crystallized from methanol. The crystals showed the absorption maxima of ergosterol and this material was thus determined by absorption at $282 \mathrm{~m} \mu$. The total sterol (mainly cholesterol) content was estimated as this crystallized material together with the material removed before chromatography. With embryo material, the ether and methylal fractions showed maxima at 235 and $282 \mathrm{~m} \mu$. In ethanol the maxima of the latter com- pound appeared at 242,260 and $296 \mathrm{~m} \mu$ and on the addition of $\mathrm{NaOH}$ peaks were present at 266 and $326 \mathrm{~m} \mu$. This chromophore is that of 3-formylindole (Morton \& Fahmy, 1959).

3-Formylindole. The addition of alkali to a solution of 3 formylindole in ethanol results in a large increase in absorption at $326 \mathrm{~m} \mu$, probably due to isomerization (Morton \& Fahmy, 1959). This increase at $326 \mathrm{~m} \mu$ may be used as a method of estimating 3-formylindole in the presence of<smiles>O=Cc1c[nH]c2ccccc12</smiles>

other ultraviolet-absorbing material. From the data of Morton \& Fahmy (1959) it was calculated that the increase at $326 \mathrm{~m} \mu$ on the addition of alkali was equivalent to an $\epsilon$ of 19610 . Fractions containing 3-formylindole were estimated by this method.

Emmerie-Engel reaction. Total tocopherol was estimated by the method of Emmerie \& Engel (1938) according to the procedure of the Analytical Methods Committee (1959). To $1 \mathrm{ml}$. of an ethanolic solution of the sample $(20-100 \mu \mathrm{g}$. of tocopherol) was added $1 \mathrm{ml}$. of $0.2 \% \alpha \alpha$-bipyridyl in ethanol and $1 \mathrm{ml}$. of $0.2 \%(\mathrm{w} / \mathrm{v}) \mathrm{FeCl}_{3}$ in ethanol, and the mixture was made up to $5 \mathrm{ml}$. The red colour was measured at $520 \mathrm{~m} \mu$ exactly $2 \mathrm{~min}$. after the addition of the $\mathrm{FeCl}_{3}$. A standard graph for $\alpha$-tocopherol was prepared and at this stage no correction was made for the presence of other tocopherols.

Thin-layer chromatography. The ubiquinone- and tocopherol-containing fractions were further fractionated by chromatography on a thin layer of silica gel with benzenechloroform $(1: 1, v / v)$ as solvent. Spots of the fraction were placed at either end of the plate and the remainder (up to $50 \mathrm{mg}$.) was applied between the two spots as a line. After development of the chromatogram with the solvent the areas in front of the spots were stained with EmmerieEngel reagent (for reducing compounds) and potassium permanganate. The silica gel in areas corresponding to stained spots was scraped off the plate and extracted with ether.

Detection of tocopherols by diazotized o-dianisidine. The method as described by the Analytical Methods Committee (1959) was used. To a solution of o-dianisidine dihydrochloride $(0.5 \mathrm{~g}$.) in water $(60 \mathrm{ml}$.) was added $6 \mathrm{ml}$. of conc. $\mathrm{HCl}$ and $12 \mathrm{ml}$. of aq. $5 \%(\mathrm{w} / \mathrm{v})$ sodium nitrite solution. Aq. $5 \%(w / v)$ urea $(12 \mathrm{ml}$.) was added to the mixture after 5 min. and the tocopherol spots were sprayed with aq. $5 \%$ $(w / v)$ sodium carbonate and then with the diazotized dianisidine solution.

Nitrosation of tocopherols. Tocopherols were nitrosated according to the method of Marcinkiewicz \& Green (1959). A small sample (0.6 mg.) of each tocopherol was dissolved in $5 \mathrm{ml}$. of ethanol, and $\mathbf{0 . 2} \mathrm{ml}$. of acetic acid was added. Aq. $2 \%(w / v)$ sodium nitrite solution $(3 \mathrm{ml}$.) was added and exactly 90 sec. later $2 \mathrm{ml}$. of aq. $20 \%(\mathrm{w} / \mathrm{v})$ potassium hydroxide solution was added. The nitrosotocopherols were extracted into light petroleum.

Paper chromatography. The ubiquinone homologues were determined with the reversed-phase paper-chromatographic system of Lester \& Ramasarma (1959). Unknown 
Table 1. Ultraviolet-absorption spectra and $R_{F}$ values of authentic tocopherols

The spectra were measured in cyclohexane. The $R_{p}$ values were for silica-gel thin layer with benzene-chloroform $(1: 1, v / v)$. The time of the run was $1 \mathrm{hr}$.

\begin{tabular}{|c|c|c|c|c|c|c|c|}
\hline Tocopherol & $\begin{array}{l}\lambda_{\max } \\
(m \mu)\end{array}$ & $E_{1 \text { \% }}^{1 \%}$ & $\underset{(\mathrm{max}}{\lambda_{\max }}$ & $E_{1 \% \text { m. }}^{1 \%}$. & $\underset{(\mathrm{m} \mu)}{\lambda_{\min }}$ & $E_{1}^{1 \%}$ cm. & $R_{F}$ \\
\hline $\begin{array}{l}\text { Tocol } \\
\alpha \text {-Tocopherol: 5,7,8-trimethyltocol } \\
\beta \text {-Tocopherol: 5,8-dimethyltocol } \\
\gamma \text {-Tocopherol: } 7,8 \text {-dimethyltocol } \\
\zeta_{2} \text {-Tocopherol: } 5,7 \text {-dimethyltocol }\end{array}$ & $\begin{array}{l}297 \cdot 5 \\
292 \\
294 \\
294 \\
290\end{array}$ & $\begin{array}{l}91 \cdot 3 \\
77 \cdot 9 \\
86 \cdot 0 \\
95 \cdot 4 \\
72 \cdot 0\end{array}$ & $\begin{array}{l}307 \cdot 5 \\
297 \\
299 \\
300 \\
297\end{array}$ & $\begin{array}{l}73 \cdot 1 \\
80 \cdot 7 \\
86 \cdot 0 \\
94 \cdot 4 \\
66 \cdot 0\end{array}$ & $\begin{array}{l}256 \\
254 \\
258 \\
257 \\
256\end{array}$ & $\begin{array}{r}5 \cdot 4 \\
10 \cdot 5 \\
13 \cdot 3 \\
8 \cdot 0 \\
12 \cdot 8\end{array}$ & $\begin{array}{l}0 \cdot 14 \\
0 \cdot 54 \\
0 \cdot 34 \\
0 \cdot 35 \\
0 \cdot 43\end{array}$ \\
\hline
\end{tabular}

ubiquinone samples, and ubiquinone-45 and ubiquinone-50 markers, were chromatographed on Whatman no. 3 paper impregnated with Dow-Corning silicone fluid no. 550 with propan-ol-water $(4: 1, \nabla / v)$ as solvent. In all cases only ubiquinone-50 was found.

\section{RESULTS AND DISCUSSION}

Identification of tocopherols. Of the chromatographic fractions derived from egg yolk those eluted by 6 and $10 \%$ ether in light petroleum contained tocopherol-like material absorbing in the ultraviolet near $295 \mathrm{~m} \mu$. These two fractions were combined and subjected to thin-layer chromatography, and two reducing compounds were detected. The two materials were eluted from silica gel and in each case a pale-yellow oil was obtained. Compound (I), $R_{F} \mathbf{0 . 5 3}$, showed absorption maxima at 292 and $297 \mathrm{~m} \mu$ with a minimum at $253 \mathrm{~m} \mu$, and compound (II), $R_{F} 0 \cdot 36$, had maxima at 294 and $300 \mathrm{~m} \mu$ with a minimum at $260 \mathrm{~m} \mu$.

Table 1 shows that compound (I) is $\alpha$-tocopherol and, further, that compound (II) could be either $\gamma$ - or $\beta$-tocopherol which have almost identical ultraviolet spectra and $R_{F}$ values. The unknown tocopherol fraction was treated with diazotized $o$-dianisidine according to the method of the Analytical Methods Committee (1959). A bluegreen colour was obtained indicating the presence of $\gamma$-tocopherol. However, since $\beta$-tocopherol does not couple to give a coloured derivative, the presence of this tocopherol cannot be ruled out.

Marcinkiewicz \& Green (1959) have reported the formation of nitroso derivatives of $\beta$ - and $\gamma_{r}$ tocopherol and their separation on paper chromatography. Accordingly the nitroso derivatives of $\beta$ and $\gamma$-tocopherol and compound (II) were prepared as described by Marcinkiewicz \& Green (1959). The yellow nitrosotocopherols were chromatographed on a thin layer of silica gel with benzene as solvent. The spots were stained with the Emmerie-Engel reagent and compound (II) gave only one reducing component, of $R_{F} \mathbf{0 . 7 6}$. Nitroso- $\gamma$-tocopherol had $R_{F} \mathbf{0 . 7 6}$ and that of nitroso- $\beta$-tocopherol was 0.56 . The egg yolk contained therefore $\alpha$ - and $\gamma$-tocopherol and the amount of each present was estimated from the ultraviolet absorption. Rama-
Table 2. Unsaponifiable lipids of egg yolk

Experimental details are given in the text. Three yolks were used for the determination. The values quoted are amounts/egg yolk.

Weight of yolk
Unsaponifiable lipids
Total sterol
Ergosterol
Cholesta-3,5-dien-7-one
Vitamin A
Ubiquinone-50
Total tocopherol
$\alpha$-Tocopherol
$\gamma$-Tocopherol

$21.9 \mathrm{~g}$. $355 \mathrm{mg}$. ( $1.62 \%$ of total wt.) $311 \mathrm{mg}$. $230 \mu \mathrm{g}$. $63 \mu \mathrm{g}$. 407 i.u. $116 \mu \mathrm{g}$. $1.00 \mathrm{mg}$. $0.698 \mathrm{mg}$. $0.302 \mathrm{mg}$.

sarma, Jayaraman \& Sarma (1961) reported a reducing compound in egg yolk which was different from $\alpha$-tocopherol or ubichromenol, and clearly this compound could also be $\gamma$-tocopherol.

Cholesta-3,5-dien-7-one. Chromatography of the tocopherol fraction on a thin layer of silica gel showed the presence of a non-reducing ultravioletabsorbing compound. This material, which had $R_{F}$ 0.14 on the silica gel, was eluted from the adsorbent and a white wax was obtained. The material showed an absorption maximum at $268 \mathrm{~m} \mu$ in cyclohexane and in ethanol there was a bathochromic shift to $278 \mathrm{~m} \mu$. In concentrated sulphuric acid this compound showed a maximum at $355 \mathrm{~m} \mu$. These spectral data are consistent with those of cholesta-3,5-dien-7-one, which Cain \& Morton (1955) found in horse liver and which has also been detected in pig testes (Ruzicka \& Prelog, 1943), pig spleen (Prelog, Ruzicka \& Stein, 1943) and ox liver (Karrer \& Naik, 1948 a,b). Ramasarma et al. (1961) found a compound in egg yolk with a peak at $265 \mathrm{~m} \mu$ and with some properties of a ring ketone. This compound is very similar to cholesta3,5-dien-7-one as described here.

The unsaponifiable lipid constituents of egg yolk are shown in Table 2 and represent $1.62 \%$ of the total egg yolk; of these lipids $87 \%$ is sterol. Gaujoux \& Krijanowsky (1932) give a value of $0.3 \mathrm{~g}$. of cholesterol/egg yolk and our result is very near this. A similar value is quoted by Levy \& Georgiakakis (1908) and thus it appears that in 
hen's eggs the cholesterol level is fairly constant. In contrast, the vitamin A content of egg yolk can vary several-fold even when the diet of the hen is standard (Hughes \& Payne, 1937). However, the value obtained, $407 \mathrm{i} . u$./egg yolk, is within the limits found by Cruickshank (1941), i.e. between 200 and 800 i.u. of vitamin A. Schönheimer \& Dam (1932) found 1 part of ergosterol/1000 parts of total sterol in egg yolk, and our value of 1:1350 is in fair agreement with their work. Cholesta-3,5-dien7-one has not previously been reported in egg yolk.

Ubiquinone-50 is present in egg yolk to the extent of $116 \mu \mathrm{g}$. and this is in close agreement with the values quoted by Ramasarma et al. (1961), 133, 127 and $79 \mu \mathrm{g}$. for three batches of eggs. It may be significant, however, that no ubichromenol or dolichol (Pennock, Hemming \& Morton, 1960) was detected in egg yolk. The relatively high concentration of $\gamma$-tocopherol in egg yolk (30\% of the total tocopherol) is perhaps surprising since the hen deposits $\alpha$-tocopherol in eggs in preference to any other tocopherol (Quaife, Swanson, Dju \& Harris, 1949). These workers found that when a hen was given equal quantities of the tocopherols the relative efficiency of transfer to the egg was $22.1 \%$ for $\alpha$-tocopherol and only $3.6 \%$ for $\gamma$-tocopherol. A batch of three farmyard eggs were examined as were the market eggs: the eggs had $0.936 \mathrm{mg}$. of total tocopherol/yolk and of this $24 \%$ was $\gamma$ tocopherol and the remainder $\alpha$-tocopherol. It is apparent that the diet of both types of birds must be rich in $\gamma$-tocopherol to achieve this relatively high level in egg yolk despite the low efficiency of transfer. Corn, containing $87 \%$ of the total tocopherol as $\gamma$-tocopherol, possibly was a major component of the diet.

Table 3 shows the transfer of these unsaponifiable lipids to the developing chick embryo during incubation and the synthesis of more lipids in some cases. The growth of the chick embryo is very slow in the first 11 days of incubation but thereafter the rate of increase in weight is quite rapid. The eggs were incubated for the required number of days and the embryos from three eggs combined. However, there is considerable variation in the stage of development of embryos of the same age. In Lillie's 'Development of the Chick' $(1953$, p. 74) it is stated that, although the total period of incubation is fairly constant at 21 days, there may be variations in (a) the rate of development of the embryo, (b) the relative rates of development of different organs, and (c) the size of the embryo. By the 12th day of development the embryo has reached the stage where all the major structural changes have taken place. On the 19th day of incubation, the yolk sac is withdrawn into the body cavity and is completely enclosed by the 20th day. The yolk sac at this stage is about one-sixth of the weight of the embryo according to Lillie's 'Development of the Chick' (1953, p. 287). The contents of the yolk sac continue to be used until about 6 days after hatching, when the yolk sac is of negligible weight. The eggs withdrawn from the incubator at 19 days in this experiment, however, contained embryos with external yolk sacs, but hatched chicks had no external yolk sac left.

\section{Table 3. Unsaponifiable lipids in the developing embryo and residual yolk}

Experimental details are given in the text. Values are total amounts in egg yolk or embryo. At 21 days, when the chicken hatches, there is no yolk left externally as the yolk sac has been withdrawn into the body cavity. Three egg yolks or three embryos were used for each determination. n.d., Not detected; t., trace.

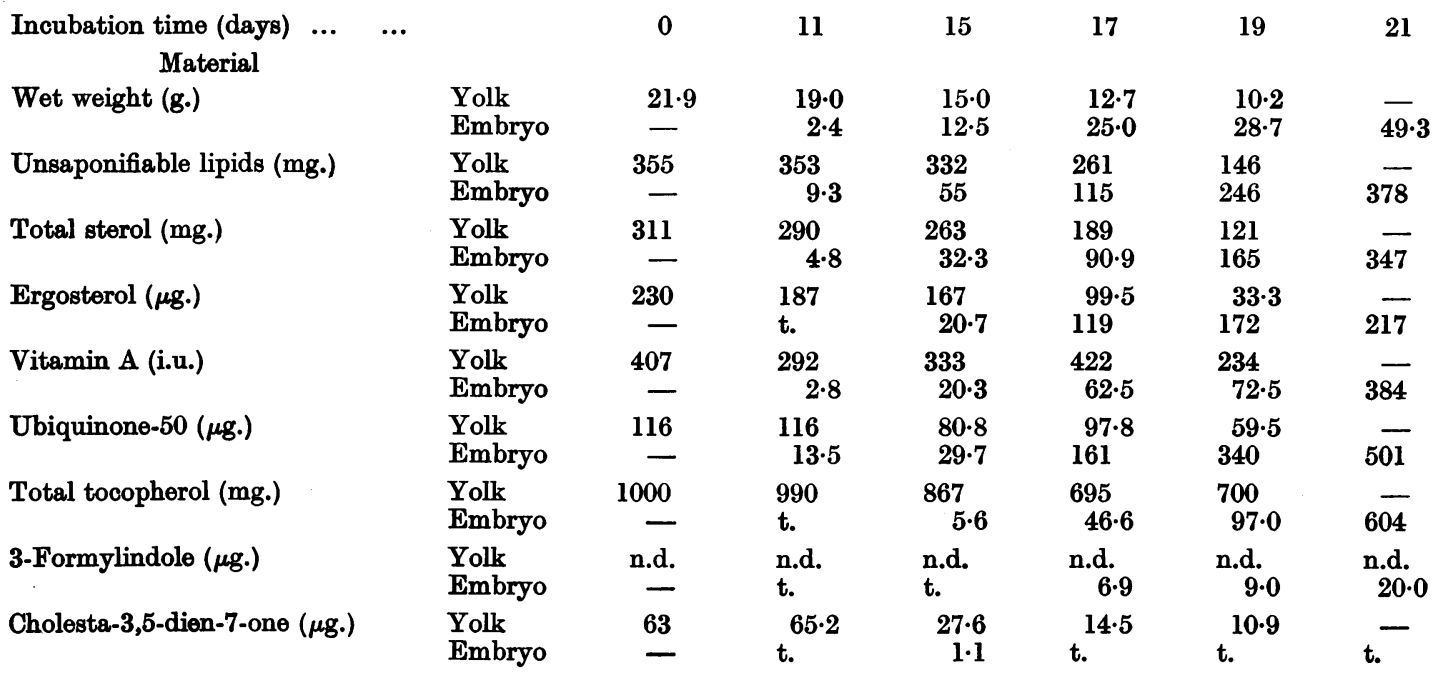


Table 4. Cholesterol and ubiquinone in the embryo

Experimental details are given in the text.

$\begin{array}{lcccccc}\text { Incubation time (days) } & \ldots & 11 & 15 & 17 & 19 & 21 \\ \text { Cholesterol (mg./g. wet wt.) } & 2 \cdot 0 & 2 \cdot 6 & 3 \cdot 6 & 5 \cdot 8 & 7 \cdot 0 \\ \text { Ubiquinone ( } \mu \text { g./g. wet wt.) } & 2 \cdot 8 & 2 \cdot 4 & 6.4 & 11 \cdot 8 & 10 \cdot 2\end{array}$

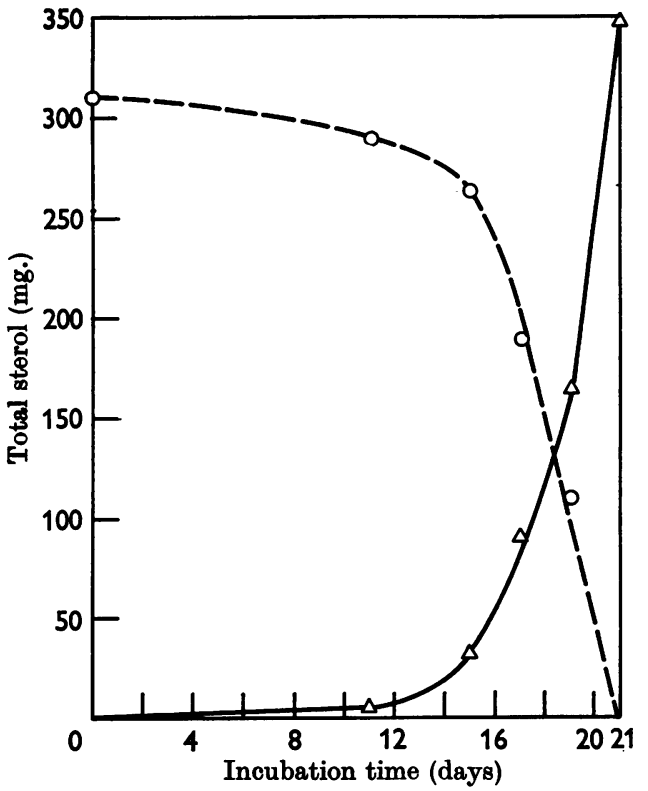

Fig. 1. Appearance of sterol in the developing chick embryo during incubation compared with the disappearance of sterol from the egg yolk. Experimental details are given in the text. Values are for total sterol/embryo or egg yolk. O, Egg yolk; $\triangle$, developing embryo.

Table 3 shows that the unsaponifiable lipids start passing into the embryo from the yolk at a considerable rate after the 11 th day of incubation. In terms of total amount, there is little difference in the quantity of unsaponifiable lipids present in the unincubated yolk and hatched chick. Table 3 and Fig. 1 show how sterol is incorporated into the embryo and it is clear that the embryo has synthesized some sterol, which amounts to not less than $11 \%$ of that originally present in the yolk. Cholesterol has great importance as a starting point for the synthesis of other steroids but there is little direct evidence for a function of cholesterol as such. Most lines of thought point to a structural role for this sterol and the need for this compound increases rapidly as growth proceeds. Table 4 shows that the amount of sterol/g. of embryo increases as the embryo continues to grow.

Ergosterol is transferred from the yolk to the embryo in the last 6 days of incubation (Table 3, Fig. 2). This compound will be utilized by the

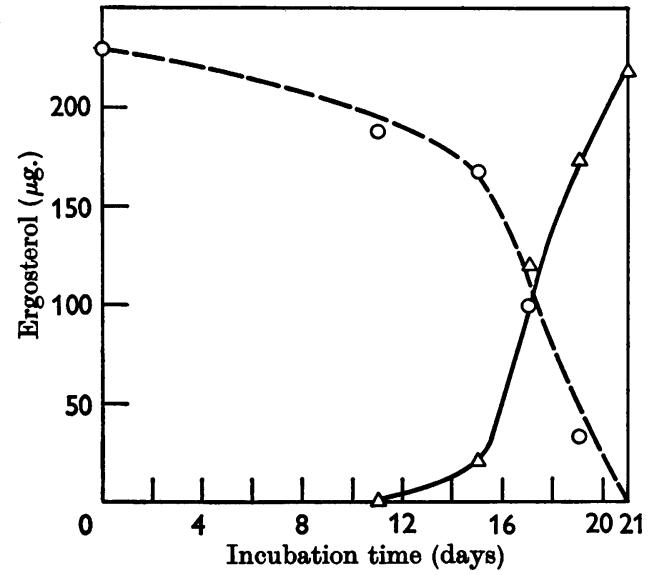

Fig. 2. Uptake of ergosterol by the developing chick embryo from the yolk sac during incubation of the egg. Experimental details are given in the text. Ergosterol values are for whole embryo or egg yolk. O, Egg yolk; $\triangle$, developing embryo.

hatched chick when it can be converted into vitamin $D_{2}$ by the action of the ultraviolet light in sunlight.

The amount of vitamin A present in the residual yolk varies greatly, but this is not surprising since the eggs taken from the incubator at certain days were not from the same batch of eggs. Vitamin A, however, is only slowly absorbed from the yolk sac by the embryo and by the 19th day the embryo contains only between 15 and $25 \%$ of the vitamin A originally in the yolk. On hatching, however, the chick has now all the vitamin $A$ originally present and this sudden increase may be accounted for by the absorption of the yolk sac into the body cavity. Parrish, Williams, Hughes \& Payne (1950) have shown that about $28 \%$ of the vitamin A present is lost during incubation and a further $45 \%$ was in the yolk sac on hatching. There would appear to be a large excess of vitamin A present in the yolk and only about one-third of that present is absorbed by the embryo up to hatching.

Table 3 clearly indicates that the developing chick embryo synthesizes ubiquinone-50 during incubation (see also Fig. 3). The ubiquinone disappears only slowly from the yolk and by the 19th day slightly over $50 \%$ of the original ubiquinone remains in the yolk sac. Ubiquinone in the embryo 
increases slowly up to the 15th day and then very rapidly up to hatching, when the embryo contains over four times as much as was originally present in the yolk. Ramasarma et al. (1961) found that, after 15 days of development, virtually all the ubiquinone originally present in the yolk had been incorporated into the embryo. They did not find any total synthesis of ubiquinone by the embryo. Fig. 3 may indicate that the yolk provides preformed ubiquinone for the embryo up till the 15th day, when the embryo begins synthesis de novo. Table 4 shows that ubiquinone increases/g. of embryo during the last 6 days of incubation as well as in total amount.

Like vitamin $A$, the majority of the vitamin $E$ in the yolk is taken into the embryo when the yolk sac is absorbed at about the 19th day. Only very small amounts of tocopherol can be found in the embryo as late as 15 days of development, but by this time relatively large amounts of the compound have disappeared from the yolk (Table 3, Fig. 4). These results may indicate that tocopherol is functioning as an antioxidant to prevent wastage of the yolk contents. The work of Green, Diplock, Bunyan, Edwin \& McHale (1961) shows that in some way tocopherol and ubiquinone synthesis are connected. In particular low tocopherol levels in tissues result in low ubiquinone levels. Therefore tocopherol may be needed by the embryo in the later stages of incubation while ubiquinone is being synthesized.

3-Formylindole was not detected in egg yolk but this compound appeared in the embryo in measurable amounts from the 17th day of incubation. Morton \& Fahmy (1959) found 3-formylindole in pancreas and spleen of several animals and it has also been detected in guinea-pig liver and kidney (Pennock, 1959). Salhanick \& Berliner (1957) detected the compound in a large feminizing adrenal carcinoma from a young man. Little is known, however, about its function or significance. If this compound were a normal artifact of isolation from proteins then it would be expected to be present in the whole egg as well as in the embryo.

Cholesta-3,5-dien-7-one disappears from the egg yolk during incubation but does not apparently appear in the embryo to any great extent. Kantiengar \& Morton (1955) fed cholesta-3,5-dien-7-one to rats and found only small amounts of the dienone in the liver. The major part of the dose disappeared to form unidentified products. Further work (Kantiengar, Lowe, Morton \& Pitt, 1955) on cockerels produced similar results. These results perhaps indicate that the disappearance of the dienone during incubation of the egg is not unexpected.

The results for the liver of 14-day and 19-day embryonic chicks (Table 5) are similar to those for the whole organism. In the 5-day period of development between these two batches of liver, ubiquinone has more than tripled in quantity and a quite large increase in the amount of tocopherol

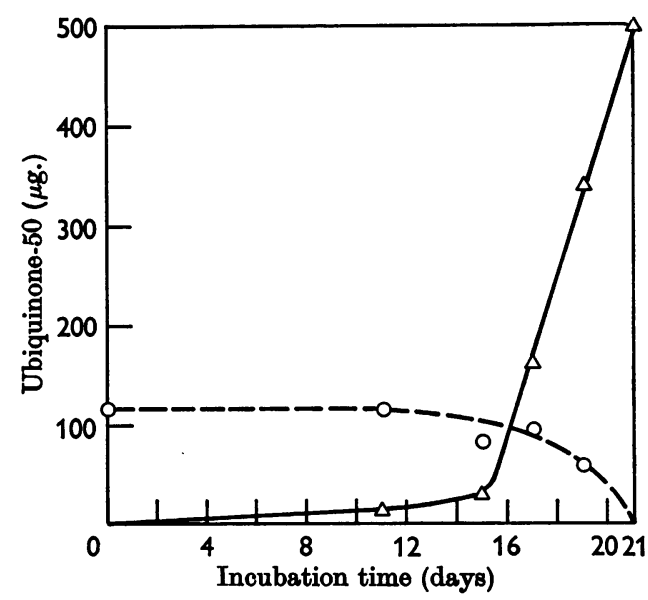

Fig. 3. Slow disappearance of ubiquinone from the egg yolk compared with the rapid production of this compound in the chick embryo during the latter days of incubation. Experimental details are given in the text. Ubiquinone values are for the whole embryo or egg yolk. O, Egg yolk; $\Delta$, developing embryo.

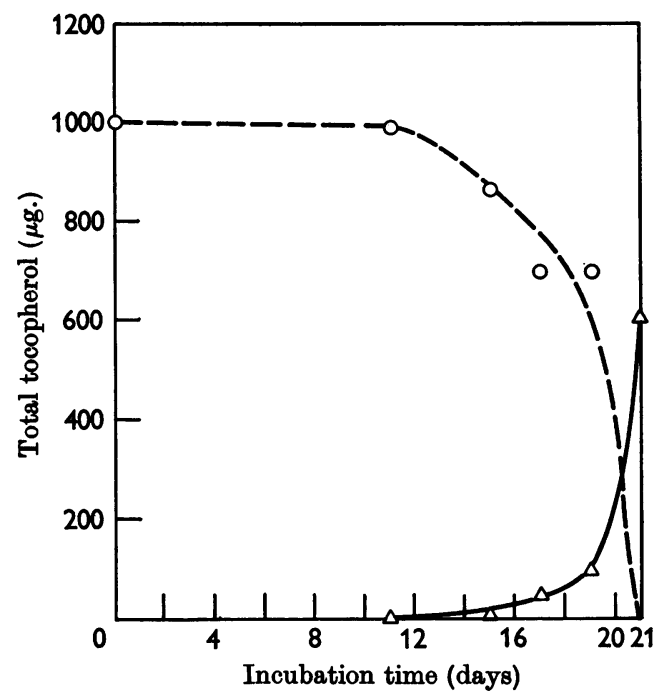

Fig. 4. Disappearance of tocopherol from the egg yolk compared with its appearance in the chick embryo. Experimental details are given in the text. The hatching chick contains only six-tenths of the total tocopherol that was originally present in egg yolk. Tocopherol disappears from the egg yolk during most of the incubation period but it only appears in the embryo in measurable quantity in the last few days of development. Values are for total tocopherol/embryo or egg yolk. O, Egg yolk; $\triangle$, developing embryo. 
Table 5. Unsaponifiable lipid present in embryonic chick liver

Experimental details are given in the text. Results for the 14-day-embryo lipids were calculated from Table 3.

Incubation time (days) ...

Compound

Sterol (mg.)

Vitamin A (i.u.)

Ubiquinone-50 ( $\mu \mathrm{g}$.

Tocopherol ( $\mu \mathrm{g}$.

3-Formylindole ( $\mu \mathrm{g}$.

Amount/g.
of liver
$6 \cdot 48$
$32 \cdot 6$
$31 \cdot 6$
$6 \cdot 75$
$0 \cdot 40$

$\cdots$

14

$\begin{array}{cc}\begin{array}{c}\text { Amount/ } \\ \text { liver }\end{array} & \begin{array}{c}\text { \% of total } \\ \text { in embryo }\end{array} \\ 1.33 & 6 \cdot 8 \\ 8.0 & 64.0 \\ 7.65 & 45 \cdot 4 \\ 1.6 & 51 \cdot 6 \\ 0.09 & -\end{array}$

$\begin{array}{ccc}\overbrace{\begin{array}{c}\text { Amount/g. } \\ \text { of liver }\end{array}} & \begin{array}{c}\text { Amount/ } \\ \text { liver }\end{array} & \begin{array}{c}\text { \% of total } \\ \text { in embryo }\end{array} \\ 17.4 & 7.33 & 4.4 \\ 50.3 & 21.3 & 29.4 \\ 100.3 & 47.4 & 14.0 \\ 51.6 & 21.8 & 22.5 \\ 2.00 & 0.85 & 9.44\end{array}$

has also taken place. At 19 days the liver is only one-seventieth of the totel weight of the embryo and still it contains two-ninths of the total tocopherol. It may well be that this is associated with ubiquinone synthesis in some way. Separation of the liver-tocopherol fraction on a thin layer of silica gel gave the two tocopherols, $\alpha$ - and $\gamma-$, in the same proportion as was originally present in the yolk, i.e. $72 \%$ of $\alpha$ - and $28 \%$ of $\gamma$-tocopherol. It can be assumed that the embryo has shown neither preferential absorption from the yolk sac nor preferential uptake by the tissues of $\alpha$-tocopherol.

Neither ubichromenol nor dolichol was found in either the whole embryo or the liver.

Ubiquinone can be synthesized completely by micro-organisms from acetate (Threlfall \& Glover, 1962). In mammals, however, although the side chain of the molecule can be built up from mevalonate (Gloor \& Wiss, 1959), attempts to show a synthesis by tissue homogenates in vitro were unsuccessful (Phillips, 1960; Gloor \& Wiss, 1960). Lawson, Threlfall, Glover \& Morton (1961) showed that ubiquinone could be synthesized in everted intestinal sacs of the rat when small amounts of ubiquinone itself were also present. This may suggest that dietary ubiquinone is broken down to give a nucleus which can be utilized in the synthesis of fresh ubiquinone by the animal. This approach is also suggested by the work of Billeter \& Martius (1960) on vitamin $K$. The synthesis of ubiquinone by a developing chick embryo, which can be considered as being free of bacterial contamination, indicates that no preformed nucleus is required. Bentley, Ramsey, Springer, Dialameh \& Olson (1961) have shown that labelled phenylanaline can be incorporated, at a very low level, into the nucleus of ubiquinone, and Gloor (1961) has shown similar results with labelled tyrosine. It is probable therefore that either or both of these aromatic amino acids can be utilized by the chick embryo.

\section{SUMMARY}

1. The yolks of unincubated eggs and the residual yolks and developing embryos from eggs incubated for $11,15,17,19$ and 21 days have been examined for unsaponifiable lipid constituents.

2. Ubiquinone, $\alpha$-and $\gamma$-tocopherol, vitamin $A$, cholesta-3,5-dien-7-one and ergosterol are reported in egg yolk.

3. Ubiquinone is synthesized by the developing chick embryo.

4. The majority of the tocopherol, vitamin $\mathbf{A}$, sterol and ergosterol is transferred from the yolk to the embryo in the last few days of incubation.

5. 3-Formylindole appears in the embryo in increasing amounts from the 17th day of incubation.

This research was supported by a grant (RG5942 C5 and C6) from the National Institutes of Health to H.R.M. J.F.P. holds a Fulbright Fellowship, and H.R.M. a Research Career Award from the U.S. Public Health Service while on leave 1962-1963 with Laboratoire de Génétique Physiologique, Gif-sur-Yvette, Seine-et-Oise, France.

\section{REFERENCES}

Analytical Methods Committee, Vitamin E Panel (1959). Analyst, 84, 356.

Bentley, R., Ramsey, V. G., Springer, C. M., Dialameh, G. H. \& Olson, R. E. (1961). Biochem. biophys. Res. Commun. 5, 443.

Billeter, M. \& Martius, C. (1960). Biochem. Z. 333, 430.

Brand, L., Dahl, C. \& Mahler, H. R. (1960). J. biol. Chem. 235, 2456.

Cain, J. C. \& Morton, R. A. (1955). Biochem. J. 60, 274.

Carr, F. H. \& Price, E. A. (1926). Biochem. J. $20,497$.

Crane, F. L., Lester, R. L., Widmer, C. \& Hatefi, Y. (1959). Biochim. biophys. Acta, 32, 73.

Cruickshank, E. M. (1941). Nutr. Abstr. Rev. 10, 645.

Emmerie, A. \& Engel, C. (1938). Rec. Trav. chim. PaysBas, 57, 1351.

Gaujoux, E. \& Krijanowsky, A. (1932). C.R. Soc. Biol., Paris, 110, 1083.

Gloor, U. (1961). Helv. physiol. acta, 19, c73.

Gloor, U. \& Wiss, O. (1959). Arch. Biochem. Biophys. 83, 216.

Gloor, U. \& Wiss, O. (1960). Biochem. biophys. Res. Commun. 2, 222.

Glover, J., Goodwin, T. W. \& Morton, R. A. (1947). Biochem. J. 41, 94.

Green, J., Diplock, A. T., Bunyan, J., Edwin, E. E. \& McHale, D. (1961). Nature, Lond., 190, 318. 
Hughes, J. S. \& Payne, L. F. (1937). Poult. Sci. 16, 135.

Kantiengar, N. L., Lowe, J. S., Morton, R. A. \& Pitt, G. A. J. (1955). Biochem. J. 60, 34.

Kantiengar, N. L. \& Morton, R. A. (1955). Biochem. J. 60, 30.

Karrer, P. \& Naik, A. R. (1948a). Helv. chim. acta, 31, 1617.

Karrer, P. \& Naik, A. R. (1948b). Helv. chim. acta, 31, 2244.

Lawson, D. E. M., Threlfall, D. R., Glover, J. \& Morton R. A. (1961). Biochem. J. 79, 201.

Lester, R. L. \& Ramasarma, T. (1959). J. biol. Chem. 234, 673.

Levy, A. J. \& Georgiakakis, N. (1908). Pflüg. Arch. ges. Physiol. 124, 585.

Lillie's 'Development of the Chick'. Brief edition revised by Hamilton, H. L. (1953). New York: Henry Holt and Co. Marcinkiewicz, S. \& Green, J. (1959). Analyst, 84, 304.

Morton, R. A. \& Fahmy, N. I. (1959). Biochem. J. 72, 99.

Parrish, D. B., Williams, R. N., Hughes, J. S. \& Payne, L. F. (1950). Arch. Biochem. 29, 1.
Pennock, J. F. (1959). Ph.D. Thesis: University of Liverpool.

Pennock, J. F., Hemming, F. W. \& Morton, R. A. (1960). Nature, Lond., 186, 470.

Phillips, W. E. J. (1960). Canad. J. Biochem. Physiol. 38, 1105.

Prelog, V., Ruzicka, L. \& Stein, P. (1943). Helv. chim. acta, 26, 222.

Quaife, M. L., Swanson, W. J., Dju, M. Y. \& Harris, P. L. (1949). Ann. N.Y. Acad. Sci. 52, 300.

Ramasarma, T., Jayaraman, J. \& Sarma, P. S. (1961). Naturwissenschaften, 48, 102.

Romanoff, A. L. \& Romanoff, A. J. (1949). The Avian Egg, p. 337. New York: J. Wiley and Sons.

Ruzicka, L. \& Prelog, V. (1943). Helv. chim. acta, 26, 975.

Salhanick, H. A. \& Berliner, D. L. (1957). J. biol. Chem. 227, 583.

Schönheimer, R. \& Dam, H. (1932). Hoppe-Seyl. Z. 211, 241.

Threlfall, D. R. \& Glover, J. (1962). Biochem. J. 82, 14 P.

Biochem. J. (1962) 85, 537

\title{
The Uptake of Cortisol by Rat Tissues
}

\author{
By D. BELlamy, J. G. PHILliPS, I. CHESTER JONES AND RUTH A. LEONARD \\ Department of Zoology, University of Sheffield
}

(Received 11 May 1962)

Steroid hormones that are released into the blood pass through all the organs of the body but may exert their major effect by action on only one or two specific tissues. This raises the possibility of the selective uptake and concentration of steroids by special 'target' cells. Although the quantity of corticosteroids in vertebrate plasma is small the distribution of these hormones between blood and tissues may be conveniently investigated with radioactive-isotope techniques.

Some of the first experiments with radioactive steroids (see Samuels, Brown, Eik-Nes, Tyler \& Dominguez, 1957) emphasized the non-uniform nature of the equilibration of exogenous hormones with the body fluids. For example, Bradlow, Dobriner \& Gallagher (1954) clearly demonstrated that $5 \mathrm{~min}$. after the injection of tritiated cortisone into mice most of the radioactivity was in the liver with only a trace in the blood. The presence of a steroid-concentrating mechanism in liver was apparent from the work of Szego (1953) on the uptake of oestrogens by liver slices, and a similar hepatic uptake of $\left.{ }^{14} \mathrm{C}\right]$ corticosteroids has since been demonstrated in vitro (Sandberg, Slaunwhite \& Antoniades, 1957). This paper gives the results of experiments on the short-term distribution of
${ }^{14} \mathrm{C}$ derived from cortisol between plasma and various tissues of the rat, and, in particular, presents details of the mechanism by which cortisol is concentrated in liver slices.

\section{MATERIAL AND METHODS \\ Distribution of radioactivity between plasma and tissues}

Animals used were male albino rats (approx. $300 \mathrm{~g}$.) from a colony maintained in the Department of Zoology, University of Sheffield. [4-14 C]Cortisol $(42 \cdot 4 \mu \mathrm{c} / \mathrm{mg}$.) was dissolved in $1 \mathrm{ml}$. of fresh heparinized rat blood and injected into the right saphenous vein. A clamp was placed on the penis and the animal kept under ether anaesthesia for $30 \mathrm{~min}$. About $8 \mathrm{ml}$. of blood was then taken from the junction of the iliac arteries with the aorta. Tissues were removed and frozen in beakers immersed in solid $\mathrm{CO}_{2}-$ ethanol. Urine was collected from the bladder with a syringe.

\section{Extraction of radioactive steroids}

Tissues. The frozen tissue was cut into approx. $1 \mathrm{~mm}$. cubes (tissue slices were used intact), $\mathrm{CHCl}_{3}$-methanol $(2: 1 ; 5 \mathrm{ml} . / 100 \mathrm{mg}$. wet wt.), together with $50 \mu \mathrm{g}$. of carrier cortisol, was added and the tissue was shaken for $2 \mathrm{hr}$. at $50^{\circ}$. Initial experiments showed that the radioactivity of the medium reached a maximum in about $1 \frac{1}{2} \mathrm{hr}$. The super- 